\title{
History
}

\section{The history and evolution of cleft surgery in India}

\author{
H. S. Adenwalla, P. V. Narayanan, C. J. Rajshree \\ Charles Pinto Centre for Cleft Lip and Palate at the Jubilee Mission Medical College and Research Institute, Trichur, South India
}

Address for correspondence: Dr. H. S. Adenwalla, Head of the Charles Pinto Centre for Cleft Lip and Palate, Jubilee Mission Medical College \& Research Institute, Trichur-680005, South India. E-mail: charlespinto@sify.com

\section{6 he longer you look back the further you look forward"}

(Winston Churchill in an address to the Royal College of Surgeons, London.)

The history of cleft surgery in India and its growth cannot be dissociated from the history and evolution of modern plastic surgery in this country. I say modern plastic surgery because there existed plastic surgeons in ancient India like Sushruta, 600 years before Christ, and there were the clay potters of Satara and a graduate of the Grant Medical College, a man called Tribhuvandas Motichand Shah in Junagadh, who performed reconstructions of mutilated noses using the median forehead flap in the $19^{\text {th }}$ century.

It is difficult to put a date to the rebirth of plastic surgery in India but if it has to be done for chronological reasons then I would say 1955 is the year of its conception. In response to a letter from the Australian Ministry of External Affairs, the Health Minister of India Rajkumari Amrit Kaur called for an enquiry. Dr. Vishwanathan, the then Director General of Health Services submitted a report to the Government of India which said that there was certainly a need in India for this fast developing specialty. As a result, Sir Benjamin Rank, Professor of Plastic Surgery, University of Melbourne, was invited. He brought with him Dr. John Tucker as his anaesthetist. This was under what was then called the Colombo plan because it was in Colombo that the foreign ministers of various South Asian Countries met and where the initial spade work and planning for this and other matters was done. It was announced that Sir. Benjamin Rank would work in Calcutta and Nagpur and surgeons interested in this field of surgery could attend. It must be stated that at that time there were a few surgeons in India who had had some exposure and training in plastic surgery in the UK. They were Dr. C. Balakrishnan, Dr. R.N. Sinha and Major Sukh. The two former surgeons had spent time with Prof. Kilner in Oxford.

Under the Colombo plan work started at the old Presidency Hospital, Calcutta in Dr. Murari Mukherjee's Unit. Dr. Sheila Rohatgi was then registrar in this department. Robin Sinha from Patna, Murthi from Vizag, Baruvah from Assam and Rustom Maneckshaw from Bombay were there. There might have been other young surgeons present at the time but their names are not in the available recorded history. Dr. Maneckshaw later did a lot for cleft care in Bombay.

Sir Benjamin Rank then moved to the Lady Harding Medical College in New Delhi and operated there with the talented orthopaedic surgeon Dr. Doraiswamy. Dr. Doraiswamy at the time was doing basic research on congenital deformities on chicks. He had succeeded in producing controlled degrees of talipes equino varus by injecting insulin in the chick embryo. Dr. Doraiswamy's early demise was a great loss to Indian surgery.

Sir Benjamin then moved to Nagpur where Dr. C. Balakrishnan had already started his work with no recognition and with the most primitive equipment. It must be remembered that Mr. Eric Peet of Oxford and Dr. William Donkin his assistant were in Secunderabad during the World War II (1939-44) and had set up a huge base hospital in pre-fabricated hutments. Most of the facial and other trauma from the North African and Burma theatres of war gravitated to this centre. During the war there were two 
army units in existence. The No.1 unit, headed by Dr. Fitzgibbon and Dr. Gibson was at Khadkee, near Pune. The No. 2 unit was under Mr. Eric Peet at Secunderabad. We are told that Dr. Balakrishnan must have inherited some of the left over equipment from this huge British army set up. Dr. Balakrishnan from Nagpur then went on to establish a major plastic surgical department at the Post-Graduate Institute at Chandigarh and is credited with a new classification and a new technique of repairing a cleft lip. A respected teacher, an able administrator and an excellent surgeon. Balakrishnan trained a large number of Indian Plastic Surgeons and propagated the principles of comprehensive cleft care. His mantle then fell on the capable shoulders of Dr. C.P. Sawhney who modified the triangular flap to mathematical precision and is one of the few Indian surgeons mentioned in Millard's three volume Opus Magnum "Cleft Craft”.

Sir Benjamin Rank's report created a lot of interest in official health circles both in Australia and in India. He organized a fellowship from the Australian Government for selected Indian surgeons to train under him. Some 15 were selected out of which 11 pursued a career in plastic surgery. Among these were R.L. Manchanda of Patiala, S.S.Rawat from Rajasthan, Brig. R.Ganguly, C. Balakrishnan, J.L. Gupta and U.S. Nayak from Madras.

In 1960, Sir Benjamin Rank returned to check on the development that had taken place in his absence, and to his great joy he found 6 full-fledged plastic surgical units established in the country. In Calcutta, under Murari Mukherjee, in Patna, under Robin Sinha, in Nagpur, under C. Balakrishnan, in Lucknow, under R.N. Sharma and in Bombay, under Dr. N.H. Antia at the J.J. Group of Hospitals and under C.J.T. Pinto at the King Edward Memorial Hospital. Two British plastic surgeons, Sir. Harold Gillies and Mr. Eric Peet contributed in great measure to the development of plastic and cleft surgery in Western India. Sir Harold Gillies also worked with Noshir Antia in Pune and at the leprosy hospital in Kondhwa and was largely instrumental in establishing with Antia, the Tata Department of Plastic Surgery at the J.J. Group of Hospitals in Bombay, which ultimately became one of the most prestigious centres in India. Other second generation plastic surgeons like Keswani, Buch and Behman Daver joined Antia in this department. The Tata endowment was only for Noshir Antia's tenure and when he retired Dr. Swaran Arora took over from him.
Ida Scudder's Vellore must not be forgotten in this narrative. Paul Brand was doing his monumental work on the leprosy hand at the Karigiri leprosarium near Vellore and an old Scotsman; Mr. McPherson started the plastic surgical department with Dr. Manohar Keswani as his first assistant. Keswani then moved to the Tata Department under Antia. The Vellore department passed into the hands of a young talented plastic surgeon, Dr. Dawson Theograj who sadly met an early and untimely death.

After the retirement of Dr. Antia and Dr. Maneckshaw, who did much for cleft care in Bombay, Dr. Behman Daver was appointed head of the plastic surgical department at the G.T. Hospital in 1973 and was professor of plastic surgery at Grant Medical College. He is one of the few Indian surgeons who trained with Millard and as a result developed special interest in cleft care. He is known for his contribution in correcting the cleft nose deformity.

The Jerbai Wadia Hospital in Bombay is called the cradle of cleft surgery in Maharashtra, where Dr. Arthur De Sa, Rustom Irani and Charles Pinto, all general-cum-paediatric surgeons were engaged in cleft surgery in a major way. Charles Pinto had also worked with Ram Ginde and imbibed a considerable knowledge of neurosurgery. Mr. Eric Peet was in Secunderabad at about the time Charles Pinto had a daughter born with a severe bilateral cleft. The parents took the child to Secunderabad, under the most difficult circumstances of travel in those war years, and several primary corrective procedures were undertaken by Mr. Peet. A relationship based on mutual respect blossomed into an abiding friendship between these two men and that marked the entry of Charles Pinto into plastic surgery, with cleft surgery as his special interest. He did a stint with James Barret Brown on a Johnson fellowship and made several visits to Oxford to train with Eric Peet. Mr. Peet then came down to Bombay on several occasions and spent much time teaching and operating at the KEM and at the Bai Jerbai Wadia Children's Hospital. Ultimately, a plastic surgical department was set up at the KEM Hospital in 1961. Charles Pinto under the influence of Eric Peet started with the straight repair of Rose Thompson (oxford modification). He went to Barret Brown, St. Louis, Missouri and picked up the triangular flap of Mirault which Blair Brown and McDowell had modified into smaller and smaller triangular flaps. For a short time he switched to the LeMesurier technique. He picked up the Millard when Sir Harold Gillies performed it for the first time in Pune, when 
he was with Antia, turned round to the audience and said "Try this one, it has merit. But note it has not been published". After that he adhered to the Millard technique.

All the cleft work at the Bai Jerbai Wadia Hospital for children was referred to Charles Pinto. Charles Pinto's versatility, dexterity and surgical skills were beyond compare. An inspiring teacher and a man of superb integrity, he commanded strong loyalties and, though he died young, he left behind a large number of well-trained plastic surgeons. Cleft work now at the Jerbai Wadia Hospital is in the hands of two well-trained plastic surgeons - Drs. Mukund Thatte and Nitin Mokal.

At the KEM Hospital, Charles Pinto was joined by K.S. Goleria, C.V. Mehendale and Suresh Tambwekar, the latter having been trained under Fenton Braithwaite. After Pinto's early demise, Dr. Goleria followed him as head of the department and has done remarkable work in cleft and craniofacial surgery. In 1962, Charles Pinto made his first trip to the Jubilee Mission Hospital, Trichur where his paediatric registrar of former days from the Jerbai Wadia was head of the surgical department. He visited what was then a small Catholic Mission hospital every year till his premature death in 1970 . The author, already a well established surgeon, and involved in cleft care, was inspired by him to further develop this service and thus came into being the Charles Pinto Centre for Cleft Lip and Palate at the Jubilee Mission Medical College and Research Institute with 40 beds entirely devoted to cleft care. This is a multispecialty centre managing all facets of cleft care and rehabilitation. Over 11,000 clefts have been reconstructed in this department since its inception. This department was initially funded by Dutch and Rotary grants, and a Dutch organization called SIMAVI. Now the major funding comes from Smile Train.

Though Dr. Charles Pinto inspired and founded this department, the work of stabilizing it was done by Dr. Manohar Keswani who in addition to pioneering burns care in India is a brilliant and extremely innovative cleft surgeon.

Also in South India was Dr. C.R. Sunderarajan, one of the first second generation plastic surgeons who did much for the propagation of reconstructive and cleft surgery. He was Prof. C. Balakrishnan's first trainee and also the first M.Ch. in Plastic Surgery in this country. When Sir Benjamin Rank again visited the Government General Hospital in Madras in 1980, Dr. Sunderarajan was the head of the department of plastic surgery.

The South Indian cleft scenario would not be complete without mention of that remarkable teacher Prof. Sam C. Bose of Madurai, also a student of Prof. Balakrishnan. Scholar and critic, with his pungent sometimes abrasive sense of humour, this man will be remembered in cleft circles for a long time to come. His contribution, his knowledge and his influence have been wide and far-reaching.

The earliest cleft work in Kerala was done by Dr. Kesavan Nair in 1940s at the General Hospital Trivandrum. He had trained in England under Hamilton Bailey. His son, Dr. Ramakrishnan Nair, was trained by Dr. Balakrishnan and joined the Medical College Hospital, Trivandrum in 1971 to continue his work. In Kerala, Dr. P.A. Thomas who was trained in Sir Archibald Mc Indoe's unit in East Grinstead, under Mr. Percy Jayes started the first plastic surgical unit at the Medical College Hospital, Trivandrum in 1971. His was the first unit to be recognized for M.Ch training in Kerala. Dr. Appukuttan, trained in Patna with R.N. Sinha, started the second M.Ch. unit at Calicut in 1980.

Dr. Kesavan Nair of Kerala had used the straight line repair. Dr. P.A. Thomas of Medical College Trivandrum had been using the LeMesurier technique to begin with and later switched on to Millard. Dr. Appukuttan has always been using the Millard technique. Dr. Ramakrishnan Nair who was Balakrishnan's trainee had been using Triple wedge technique. Most of Balakrishnan's trainees follow the modified triangular flap (Triple Wedge).

A centre of cleft excellence now stands at the Sri Ramachandra Medical Centre in Madras, an infant department of four years' standing which has achieved remarkable maturity mainly due to the dynamic administrative qualities and professional skills of a young surgeon, Dr. Jyotsna Murthy who was born in Gujarat, was trained in Bombay by Ravin Thatte, in Paris under Rene Malek and in England with Henry Golding, and now travelling all over the world in her hunger for mastering her craft.

Dr. C.N Malla in Chandigarh, Dr.R.S. Thind in Patiala and Dr. R.K.Keswani in Rohtak also made considerable contribution to cleft work in India. In the 1970s, Dr. J.R. Jaju pioneered cleft craft at the Civil Hospital in Ahmedabad and influenced the development of cleft surgery in that area. 
Dr. A. Dugal Dias of the Sion Hospital started his department a little after the other major departments started in Bombay and his worthy successor Dr. Ravin Thatte, one of the keenest thinking and thought provoking plastic surgeons in this country contributed to the progress of cleft surgery in big measure. Dr. Mukund Jagannathan, the present head, pursues the same interest with remarkable zeal.

In the early years of cleft surgery in India, general surgeons and paediatric surgeons made a positive contribution to the development of cleft surgery. In Bombay, Dr. Parmar, Arthur De Sa, Rustom Irani and Charles Pinto worked on clefts. In 1962, in the South, Dr. Raman Nair, trained by Keisewetter in Philadelphia, pioneered the first paediatric surgical department in Trivandrum and came out with what to my mind was cleft work of a very high order, comparable and often better than the best plastic surgeons of the day. Many of his first generation paediatric surgical trainees kept up his standard of work. His surgical dexterity, skill and administrative ability were of a very high order.

While the role of maxillo-facial surgeon is being mentioned, one must not forget that doyen of maxillofacial surgery Dr. Mino Ginwalla, trained at the McGill University, Montreal. He came back to India to become the Head of the Maxillofacial Department at the Nair Dental and Medical College Hospital and later rose to be its Dean. He did pioneering work in cleft surgery and enthused the maxillofacial surgeons to take up cleft work.

In the year 2000, Smile Train came into the picture creating tremendous enthusiasm for comprehensive cleft care. Quality of work improved all over the country, the safety protocol was stepped up and funds became more readily available. Sixty Smile Train partner Centres cropped up all over India and the task of cleft surgeons became much easier. Smile Train is responsible for the repair of over 40,000 cleft children in this country. Maxillofacial surgeons, who were mainly doing alveolar bone grafts and orthognathic work on clefts, came into primary cleft work. Major centres were started by Dr. Krishna Shama Rao in Mangalore and Dr. Gosla Reddy in Hyderabad. These and other maxillofacial surgeons in India were inspired and guided by Mr Anthony Markus of Poole Dorset, UK and Dr. Nabil Samman of Hong Kong. Dr. Varghese Mani of Trichur must be mentioned for his pioneering work in cleft related orthognathic surgery in South India.

There have been a host of contemporary foreign surgeons who have inspired and lent a helping hand to cleft surgeons in this country, outstanding amongst them are Mr. Ian Jackson, Prof. Samuel Noordhoff, Mr. Anthony Markus and Mr. Brian Sommerlad.

The second landmark was the establishment of the Indian Society of Cleft Lip, Palate and Craniofacial Anomalies by Dr. Suresh Tambwekar in Bombay in March 2002. However the idea of founding such a society was first suggested by Dr. Gunaseelan of the Ragas Institute, Madras, 8 years before it was founded by Dr. Tambwekar with great personal effort and sacrifice. The fact that the Asian Pacific Cleft Conferences will be held in India in the year 2007 shows that cleft surgery has come into its own in this country.

With the volume of work available in India, it is possible that in the near future the quality of cleft work will compare with the best in the world. Where we are found wanting is in documentation and research. It is expected that this deficiency will be corrected by the Donor Organizations and by the Indian Society of Cleft lip, Palate and Craniofacial Anomalies.

This short history has been compiled making every effort to include the names of all the surgeons who have contributed significantly to cleft surgery in this country. However, it is indeed inevitable that some deserving names will have been left out. Any such omission is unintentional and regretted by the author. 